\title{
Determining the Number of Refugees to Be Resettled in the United States: An Ethical and Policy Analysis of Policy-Level Stakeholder Views
}

\author{
Rachel Fabi ${ }^{\mathrm{a}}$ (D), Daniel Serwer ${ }^{\mathrm{b}}$, Namrita S. Singh ${ }^{c}$, Govind Persad ${ }^{\mathrm{d}}$, Paul Spiegel ${ }^{\mathrm{c}, \mathrm{e}}$, and \\ Leonard Rubenstein ${ }^{\mathrm{e}, \mathrm{f}, \mathrm{g}}$ \\ ${ }^{a}$ Center for Bioethics and Humanities, SUNY Upstate Medical University, Syracuse, New York, USA; ${ }^{b}$ American \\ Foreign Policy and Conflict Management Programs, the Johns Hopkins School of Advanced International \\ Studies, Washington, DC, USA; 'Department of International Health, Johns Hopkins Bloomberg School of \\ Public Health, Baltimore, MD, USA; ${ }^{\mathrm{d} S t u r m ~ C o l l e g e ~ o f ~ L a w, ~ U n i v e r s i t y ~ o f ~ D e n v e r, ~ D e n v e r, ~ C O, ~ U S A ; ~}{ }^{\mathrm{e}}$ Center for \\ Humanitarian Health, Johns Hopkins University, Baltimore, MD, USA; ${ }^{f}$ Johns Hopkins Bloomberg School of \\ Public Health, Center for Public Health and Human Rights, Baltimore, MD, USA; ${ }^{9}$ Berman Institute of \\ Bioethics, Johns Hopkins University, Baltimore, MD, USA
}

\begin{abstract}
Through engagement with key informants and review of ethical theories applicable to refugee policy, this paper examines the ethical and policy considerations that policy-level stakeholders believe should factor into setting the refugee resettlement ceiling. We find that the ceiling traditionally has been influenced by policy goals, underlying values, and practical considerations. These factors map onto several ethical approaches to resettlement. There is significant alignment between U.S. policy interests and ethical obligations toward refugees. We argue that the refugee ceiling should be restored to historical norms, and that there exists a corresponding obligation to counter negative public perceptions about refugees and the costs of resettlement.
\end{abstract}

\section{KEYWORDS}

Refugee; resettlement; humanitarianism; justice; ceiling

\section{Introduction}

In November 2019, the Trump administration announced that it was curbing the ceiling on refugee admissions for Fiscal Year (FY) 2020 to 18,000, the lowest ceiling sought by a president since the Refugee Act of 1980 gave American presidents the authority to set admission numbers (Trump, 2019). This new low broke the record the Trump administration had previously set by establishing the ceiling for FY 2019 at 30,000, which in turn broke the FY 2018 record of 45,000 (Hirschfeld Davis \& Jordan, 2017; U.S. Department of Health and Human Services, 2018). This historically low refugee cap raises a variety of ethical and policy questions about how the number of refugees admitted to the United States (U.S.) should be determined, and what that number should be. Through interviews with key informants who have extensive professional experience involving the resettlement process, this paper explores the moral and policy considerations that these informants believe should bear on these questions. Consistent with the theoretical literature, we find that there are competing moral and policy considerations relevant to the determination of the number of refugees and the ceiling-setting process. We find that respondents believe that resettlement furthers foreign and domestic policy goals and aligns with the national interest, and 
that politics can be a barrier to, or facilitator of, increased resettlement. By mapping our findings onto various theoretical frameworks that attempt to explain moral obligations toward refugees, we conclude that respondents' perspectives support the U.S. having a dual obligation both to accept significantly more refugees than it currently does and to shape public opinion regarding refugee resettlement to reduce the (false) perception of the associated costs.

\section{Background}

\section{Historical context}

The evolution of the U.S. refugee resettlement process, and the ethical and policy considerations driving it, must be understood in the context of the original resettlement system and its justification. The current international refugee regime dates back to the aftermath of World War II, when the United Nations established the United Nations High Commissioner for Refugees (UNHCR) and approved the 1951 Convention Relating to the Status of Refugees. Although the original Convention applied only to European refugees who had been forcibly displaced by the war, the 1967 Protocol Relating to the Status of Refugees removed the geographic and temporal restrictions on the definition. According to the current UNHCR definition, a refugee is someone outside their country of origin who, "owing to well-founded fear of being persecuted for reasons of race, religion, nationality, membership of a particular social group or political opinion," is unable or unwilling to return to their home country. (United Nations \& United Nations, 1951).

The U.S. has signed and ratified the 1967 Protocol. Congress later enacted the Refugee Act of 1980 in order to "provide a permanent and systematic procedure for the admission ... of refugees... and to provide comprehensive and uniform provisions for the effective resettlement and absorption of those refugees who are admitted" (U.S. Code, $\$ 101,1980$ ). The Refugee Act adopts the Convention and Protocol definition of refugees for U.S. policy and set the admission ceiling to 50,000 per year between FY 1980 and FY 1982, and included provisions for the president to increase that ceiling in the event of an "emergency refugee situation" (U.S. Code, $\$$ 207, 1980).

There are currently over 70 million forcibly displaced people worldwide, the highest number ever recorded; over 25 million of them are recognized refugees (UNHCR, 2019). As the number of refugees increases, so does the urgency of addressing their needs. Now, when the demand for resettlement is at an all-time high, the U.S. must determine the number of refugees it will admit and whether to commit resources toward finding more durable solutions for refugees abroad.

The number of refugees that the U.S. admits for resettlement each year has historically been determined through a complex process that involves both the legislative and executive branches of the U.S. government, as well as various non-governmental organizations at the local, national, and international levels. Recent reporting on the ceiling-setting process described months of "meetings, position papers, and constant recalibrations" involving the State Department, the National Security Council, the Department of Homeland Security (DHS), and other stakeholder agencies (Blitzer, 2017). Traditionally, (Blitzer, 2017) the number would then be presented by the State Department to the President, who makes the ultimate decision regarding the refugee admissions ceiling. (8 US Code $\$ 1157,2011$ ). The President is statutorily obligated to engage in "appropriate consultation" on the matter with the Judiciary Committees of both the House of Representatives and the Senate (8 US Code $₫ 1157,2011$ ). Between 1996 and 2016, this process yielded an annual ceiling between 70,000 and 90,000, although this ceiling was not always met (Migration Policy Institute, 2019). 


\section{Ethical theory}

Although the literature on ethical responsibilities that states owe refugees is vast and diverse, we highlight four paradigmatic approaches to the question of obligations to resettle refugees and how such obligations are generated. These theories were chosen for inclusion because they encompass a range of plausible views on obligations toward refugees that emphasize the concept that refugees make legitimate moral claims on others. We did not include theories that allow the exclusive prioritization of co-nationals to the exclusion of refugees' interests. The four views described also represent the most common approaches to the question of what is owed to refugees in the moral and political theory literature (Hosein, 2019; Fine \& Ypi, 2019). The proposed bases in ethical theory for a duty to resettle considered below are humanitarianism, a duty to repair, the legitimacy of the international state system, and human rights.

The first theoretical approach to refugee resettlement appeals to the principle of humanitarianism, which is a formalization of an intuitive and widely accepted obligation to help people in need, particularly when the costs of doing so are low. To say that this principle is intuitive is not to reject its grounding in more fundamental ethical principles, but rather to recognize its broad appeal. In addition to requirements that individuals help strangers in need regardless of their nationality (as with the biblical story of the Good Samaritan), many moral and political theorists recognize that this need-based principle generates state obligations toward refugees (see, e.g., Betts \& Collier, 2017; Carens, 2013; Gibney, 2004; Miller, 2016). One such scholar is Matthew Gibney, who espouses the humanitarian principle as the best foundation for responsibilities to refugees, and argues that humanitarianism obligates wealthy states to significantly expand their resettlement efforts for vulnerable refugees and others in need of asylum (Gibney, 2004, p. 237).

The second approach to determining duties to refugees appeals to a duty to repair, which is a conception of justice whereby obligations are generated when one party is responsible for harms to the other. In the case of refugees, a duty to repair would be generated when one country's conduct has causally contributed to displacement and the production of refugees. This causal relationship can most directly be linked to actions such as military intervention (as with, for example, U.S. military action in Vietnam, Iraq, or Afghanistan (Carens, 2013, p. 195), or less directly through such vehicles as climate-altering carbon emissions that lead to conflicts over increasingly scarce resources (as some have argued is a factor in the Syrian civil war) (Cane et al., 2015). Appealing to a duty to repair in such cases would require the destabilizing country to make reparations for the effects of displacement. There may, however, be disagreement over the form that these reparations take; it is plausible that a country's duty to repair could be fulfilled in multiple ways, including accepting refugees or contributing to maintaining them in other countries, but also through actions aiming to end the violence and persecution that created refugees in the first place, or through other compensation to the injured parties.

The third approach suggests that obligations toward refugees "arise as conditions of the political legitimacy of the international order of states considered as a global regime of governance" (Owen, 2016, pp. 269-91). On this view, the structure of the international state system exists to benefit the citizens of each nation, and when some nations fail to protect the human rights of their members (or, indeed, explicitly persecute some of their members), it is a failure of the system. This failure must be addressed by other members of the international community if the system is to maintain legitimacy. As political theorist Joseph Carens explains it, "because the state system assigns people to states, states collectively have a responsibility to help those for whom this assignment is disastrous" (Carens, 2013, p. 196). Carens argues that this responsibility entails a prima facie duty to admit refugees, although as above, others may not agree that resettlement is the only way for a state to discharge this duty. This position also entails a significant collective action problem, as parties may debate who, in the international state system, should actually take responsibility for protecting the human rights of refugees. 
Table 1. Key Informants.

\begin{tabular}{lc}
\hline Role & Count* $^{*}$ \\
\hline Former State Department leadership & 3 \\
Resettlement organization leadership & 1 \\
Advocacy group leadership & 3 \\
Executive branch official & 2 \\
Think tank & 7 \\
UNHCR leadership & 1 \\
Senate foreign relations senior staff & 1 \\
House senior staff & 1 \\
\hline
\end{tabular}

*Note that some key informants fell into multiple categories.

A fourth approach is the international human rights paradigm grounded in concepts of human dignity, as reflected in the Universal Declaration of Human Rights (UN General Assembly 1948). In the years that followed the Declaration, international treaties that created legal obligations of states to protect, respect, and fulfill these rights. The Declaration and treaties recognize a right of all people to leave their country, but because the treaties focus on the obligations toward people within their borders, they do not guarantee a right to enter another one. Nevertheless, they create powerful obligations of states not to discriminate in all government policies and practices, including in decisions to admit migrants on the basis of race, religion, ethnicity, nationality, place of birth, and similar factors. Thus, a human rights framework is germane to the extent that the government seeks to limit or deny refugee admission based on these factors.

While these approaches are by no means exhaustive, they do represent four predominant approaches in the moral and political theory literature to refugee resettlement and the obligations of states. Other approaches not included here are a strict nationalist account that exclusively prioritizes obligations to co-nationals; utilitarian accounts that would require that nations expend resources on alleviating global poverty and the causes of displacement rather than accepting refugees for admission (Pogge, 1997); and a cosmopolitan and utilitarian account that nations must accept unlimited numbers of refugees until the marginal utility of citizens is equal to the marginal utility of refugees (Singer \& Singer, 2010).

Unlike these excluded theories, the theories we include above were chosen because the demands they make on nations are politically realistic and actionable, and therefore of more practical ethical and policy use. To what extent these and other approaches factor (or should factor) into the actual decision-making processes of U.S. policymakers, in the context of other policy goals and resource constraints, is the subject of the research findings detailed below.

\section{Methods}

This study utilized a qualitative methodology to capture in-depth attitudes and experiences of decision-makers and stakeholders involved with U.S. refugee admissions. Efforts were made to recruit interviewees with substantial responsibilities for refugee issues from across the political spectrum, including people with first-hand knowledge of the processes by which refugee resettlement is decided. Key informant interviews were conducted with current and former officials in Democratic and Republican administrations, Congress, and analysts in a range of positions and across sectors, including federal government agencies, left- and right-affiliated think tanks, UN bodies, refugee agencies, and advocacy groups (see Table 1). Political-level Trump Administration officials from the Domestic Policy Council, the State Department, and the Department of Homeland Security did not respond to or declined repeated requests for interviews without offering reasons, but two government employees currently serving below the political level in two different U.S. government agencies did agree to anonymous interviews. Official Administration views favoring lowered refugee resettlement were already well known and documented at the time of the interviews. 
Respondents were recruited using a snowball sampling approach that built on contacts within the study team and those interviewed. Interviews were conducted using a semi-structured interview guide that covered respondents' professional role and duties, views on which criteria should be considered in determining refugee admissions, how numbers of admissions are decided on, and which values are prioritized during the process, among other topics.

Sixteen respondents were interviewed for approximately 45-60 minutes. In total, 13 interviews were conducted with 16 respondents, as two were group interviews. Interviews were conducted either in person or over the telephone, and all but four agreed to be audio-recorded and transcribed for analysis. The interviewer took extensive notes for those four interviews that were not recorded. This study was deemed exempt by the [blinded for review] IRBs, and respondents were informed of the purpose and scope of the project, confidentiality of data collected, and their right to refuse participation and/or audio-recording. Interviews were conducted between November 2017 and September 2018. Team members analyzed the interviews using qualitative content analysis and constant comparison method for thematic analysis (Charmaz, 2006; Field \& Morse, 1995). Credibility checks were conducted (Patton, 1999).

\section{Findings}

Engagement with key informants yielded three major factors that key informants felt affected or should affect the resettlement of refugees and the determination of the ceiling number. These factors were (1) policy goals; (2) underlying values; and (3) practical barriers to and facilitators of resettlement. Additionally, respondents were asked for their considered judgment of what the number of refugees to be resettled should be. Because of the wide-ranging and unstructured nature of this qualitative inquiry, as well as the small sample size, relative rather than exact quantifications of the frequency of the various themes and subthemes are presented.

\section{Policy goals}

\section{Foreign policy goals}

The foreign policy goals respondents believed should be considered when setting the refugee ceiling included: influencing the refugee policies of other countries; improving host country stability; and standing by allies and historical commitments. All of these relate to the cross-cutting theme of signaling solidarity. These goals have evolved from the time when, according to some respondents, refugee policy was an expression of Cold War politics.

Many respondents indicated that the U.S. demonstrated global leadership by accepting refugees and that this leadership was necessary to build "resilience" in the global refugee system (Respondent 4 (R4)). One respondent from an NGO involved in the resettlement process stated that "There's a value in recognizing that if the global program is something that needs to exist, we must lead in that in order for it to not fail" (R2). Another respondent with experience on the National Security Council echoed this sentiment, saying "Part of the strategy and thinking about this was [that] we need to increase what we're doing to push other countries to increase what they're doing so that we can actually create a certain degree of resilience around the world" (R4). Although this argument was common, it was not universally held. One respondent from a think tank argued that while American refugee policy can influence that of other nations, it should not be the U.S.'s responsibility to lead in this way.

Another foreign policy goal that respondents said could be achieved through resettlement was stabilizing countries, especially friends or allies, currently hosting enormous numbers of refugees due to their geographic proximity to refugee-producing states. One respondent from a think tank acknowledged that "[Resettlement] asserts American leadership... It does help allies who are in that strain" (R5b). Another described the logic of this argument as follows: 
I think that another critical component is weighing the opportunities and the risks of taking more or less from specific countries in relation to the stabilizing impact it can have on those countries. So for example, if you have a key ally like Jordan where one in every eleven residents of the country are a refugee, ... taking 6,000 people out of Jordan instead of 3,000 next year makes sense, not only because of the good of saving 3,000 more lives but because this will enable Jordan. It will send a political signal to Jordan that we are supporting them by taking the most vulnerable cases. (R2)

Like this respondent, others recognized that resettlement is often useful for "signaling" solidarity with refugee-hosting allies, and is thus in some ways more symbolic than practically helpful. However, signaling solidarity may also encourage other countries to accept refugees, which is a possible practical outcome.

\section{Domestic policy goals}

In addition to these foreign policy goals, respondents indicated that determining the number of refugees resettled also implicates two possible domestic policy goals: the promotion of national security and the furtherance of anti-immigrant policies.

The claim that refugees (and other immigrant groups) pose a security threat has been invoked by the Trump Administration to justify reducing the number of refugees admitted and issuing executive orders excluding entry visas for people from several predominately Muslim countries. It has also led to the reviews of resettlement procedures required by those same executive orders. Only a minority of respondents held the view that lowering the refugee ceiling advanced national security. The majority believed that, given the thoroughness of vetting, refugees do not pose a national security threat. One summarized this position, noting that "when you look at the numbers of refugees historically that have been arrested or charged with any kind of terrorism event, it's absolutely minuscule" (R4). Another respondent suggested that the Trump administration's position actually increases national security risks: "if we are sending a message that Muslims are not welcome here, [that signals] to ISIS that we reject Muslims" (R2).

A small number of respondents indicated that reducing the number of refugees admitted each year could improve national security by reducing risk, no matter how small it is. One argued that: "If you have an immigration program, by definition, you're going to have immigrants who are going to commit criminal acts including immigrants who are going to commit acts of terror... So the only way you don't have that is you don't have an immigration program" (R1). But the respondent added that if it eliminated its immigration program, "the United States... just wouldn't be the powerhouse of a country that we are" (R1).

Respondents also identified a potential domestic political goal, based on statements by the President, of limiting all immigration. One respondent said "The decisions of the Trump administration... are simply based [on] political calculations that setting up refugees as some kind of a threat will be politically useful" (R3). Another respondent noted that "The Trump administration's politics would be to have lower numbers because that's one of their political stances, obviously to reduce immigration" (R11).

\section{Underlying values}

The second major theme discussed by respondents was the values that underlie the refugee resettlement program. The most commonly mentioned values were protecting the vulnerable, promoting diversity, and demonstrating fairness and reciprocity toward refugees who have a historic association with the U.S. Protection of vulnerable people who are in danger has traditionally been an explicit priority of U.S. refugee policy (HHR, 2012) and was embraced even by those who oppose expansion of refugee resettlement. This value is premised on universal obligations held by and due to all human beings and related to international humanitarian principles of impartiality and humanity (International Federation of the Red Cross and Red Crescent, 2018). One 
respondent said "One of the underlying principles of international humanitarian ... assistance [is] the principle of impartiality, which is... based on need, and the principle of humanity, which is that ... we have an obligation to the person 10,000 miles away from us" (R1). This respondent observed that protecting the vulnerable applies equally to all humans, no matter where they are. This sentiment was shared by a respondent from a think tank who said that "The number one value is that the ethical or moral worth of a human being has nothing to do with their nationality... . the U.S. government would be at least partly responsible for the bad things that happened to them" (R13). This rationale reflects a suggestion that the U.S. is morally culpable when it does not accept vulnerable refugees or asylum seekers. In addition to NGO and think tank respondents who cited vulnerability, a Trump administration official said that vulnerability is first and foremost among factors that determine resettlement (R7).

Respondents disagreed, however, on how vulnerability should be defined and determined, with some tying it to medical need or imminent danger while others felt that the inability to return home was a more appropriate indicator of vulnerability. One respondent argued that for people who could not achieve permanent status in Nepal, "their vulnerability was... [that] there was no durable solution. None of those people would ever be allowed to return. And Nepal was holding extremely firm to the fact that nobody would ever be made a citizen... That's another type of vulnerability" (R11).

Some respondents qualified how vulnerability as a criterion should be applied in practice. A respondent with experience working with Congress argued: "I don't think I should be naive and say, 'Oh, it's just some vulnerability,' because ... an endless number of people are vulnerable” (R12). This respondent still prioritized vulnerability, but believed that it must be weighed alongside political and practical limitations. Another respondent also pushed back against vulnerability as the exclusive determinant, asserting that "I don't think that should be the only criterion because I think if you're going to resettle refugees in this country they do need strong communities, and I don't think you get strong communities if you're only bringing in... the old and the widows and orphans" (R9). This view relates closely to another consideration that some respondents believed deserved weight: giving people with family connections in the U.S. priority. One respondent observed that refugees with family connections "might not be the most vulnerable, they might not be the most pathetic cases, but due to family ties that would help with the integration, the assimilation, absorption." (R11).

The intrinsic and extrinsic value of diversity, including the diversity that refugees brings to the U.S., were frequently discussed by respondents. One respondent observed that "We're an immigrant country. I think there's tremendous value in extending our hand... I think we end up enriching our society as a consequence in really significant ways" (R4). This respondent suggested that the diversity of the U.S., which is a product of immigration, is supported by resettlement. Another respondent said: "I've seen the vibrancy that refugees can bring to a place... And so, to me, refugees make our country stronger, and I think that's valuable." (R11). Although respondents did not see national vibrancy as a goal of resettlement, they believed this unintended consequence is itself valuable.

Other respondents discounted the value of diversity; one respondent from a think tank argued that "the Obama administration was a liberal administration and it viewed diversity, for instance, as good in and of itself... Whereas conservatives would say there is a culture and norms and traditions that... have served us well in many situations" (R5b). The idea that American "culture" is something that should be preserved was less commonly expressed than the argument in favor of diversity.

At the same time, all respondents believed that demographic characteristics such as race or religion should not be considered when making resettlement determinations except insofar as they were responsible for a person's refugee status (e.g., if a particular race or religious group faced persecution on that basis). One respondent who formerly worked at the State Department 
argued that "we have a situation where you're going off animus as a negative motivation. Meaning we don't want people of a certain religion in our country... [and] to have a blanket opposition to any group of people from any country because of their religion... I think is wrong [and] wrongheaded" (R6). They rejected President Trump's rhetoric about religious criteria for immigration as unacceptable. Even respondents who generally believed that the admissions ceiling should be lower agreed that "there should be no religious test. The current criteria that cite fear of persecution for reasons of religion, national origin, politics, and race are okay" (R2). Other characteristics that were generally (though not always) considered off-limits included education and skills as well as nationality; one respondent from a human rights NGO stated that "there should not be any kind of criteria that have to do with making sure the person has a certain education level, or professional skills, restrictions based on their religion, or their nationality, or anything discriminatory" (R3).

Views diverged on whether a refugee's ability to assimilate to 'American culture,' that is, the ability to adapt her beliefs and behaviors to match those prescribed by American norms, should be a primary determinant of resettlement, even if it reduces cultural diversity. A respondent from a think tank argued that "I think it should be based primarily on the ability to assimilate" (R5a). Several other respondents rejected this idea, arguing that "Assimilation and integration ... seems to be fairly rapid even among very poor immigrants who are very low educated who have quite diverse opinions of the United States... By the second generation there's no statistically significant difference" (R13).

Many respondents believed that the American refugee resettlement program is and should be based on an underlying value of fairness and reciprocity toward refugees who have a historic relationship to the U.S. Most often, respondents saw the U.S. as owing reciprocity obligations to refugees who previously aided American interests. One respondent from a think tank argued that the U.S. has a moral obligation to help people who have helped the U.S., such as those who aided the military in Iraq and Afghanistan (R10). Others extended this obligation to refugees from conflict zones where the U.S. was involved regardless of whether the refugee directly aided the U.S. A respondent affiliated with the Senate Foreign Relations Committee indicated that "for our partners where we've mucked up situations like Iraq, and we went into Vietnam, and we were in Afghanistan, I do think that there is some kind of relationship that we do have. Maybe a moral obligation to tend to that" (R12).

\section{Resettlement barriers and facilitators}

In addition to the moral and policy considerations that respondents stated should affect the determination of the refugee ceiling, a number of practical factors were reported to help or hinder resettlement. These practical factors include processing capacity, which is affected by both budget and political factors, as well as community factors.

Many respondents described the processing capacity of the U.S.'s resettlement system as a limiting factor that affects the refugee ceiling determination, and most agreed that it was directly linked to the resettlement budget. A respondent from a think tank described the budget as the key factor that determines processing capacity, with a caveat about costs of resettlement:

You talk about capacity on both ends, overseas and here domestically. And then you talk about budget because it's very expensive to resettle a refugee... So you have to say is this money best spent resettling a marginal number of refugees or is it better spent helping more refugees overseas a more efficient use of the money? (R5c)

The suggestion that the budgetary limitations on capacity to resettle might lead the U.S. to provide aid to refugees overseas instead illustrates the challenging tradeoffs that the U.S. faces in some cases regarding the economics of resettlement, which is more expensive than providing overseas aid per refugee assisted. 
Table 2. Endorsements of numbers to be resettled.

\begin{tabular}{lc}
\hline Range & Number of respondents endorsing range \\
\hline Did not specify & 5 \\
$0-30,000$ & 1 \\
$30,000-70,000$ & 2 \\
$70,000-110,000$ & 3 \\
$110,000+$ & 4 \\
No ceiling & 1 \\
\hline
\end{tabular}

Respondents indicated that politics plays a role in determining budget, and hence capacity to process refugees, including security vetting. A respondent from another think tank said:

The capacity of the government agencies to run the program, particularly [DHS] which has the responsibility for vetting people, that's a political decision. Do you give [DHS] the resources they need to vet the number of people that have been agreed to in the presidential determination? The Obama administration [did]. The Trump administration doesn't. (R9)

Limiting resources needed to properly vet refugees overseas at Obama-era levels resulted in the reduced numbers resettled in the Trump Administration, which are well below even the reduced ceiling.

The effect of politics on the domestic resettlement budget was also discussed by some respondents; one observed of resettlement agencies that their capacity is "a question of how much money we're going to give them. The answer is they have an infinite expanse of capacity... [but] it's been so politicized" (R1). The view that the recent increased politicization of the resettlement process has decreased resettlement agencies' capacity to integrate refugees into communities was commonly expressed by respondents. Some respondents described the potential downstream effects of this reduction in capacity as "decay" that could result in a loss of resettlement infrastructure, keeping the capacity of resettlement agencies low in the future regardless of potential changes in the political climate. One respondent described this effect, saying that in the wake of the ceiling reduction to 45,000: "agencies now are closing... or will be closing. And there will be places where there was only one site and maybe that will close... So there will be some loss of infrastructure and expertise" (R11).

A related theme is the ability and willingness of communities to absorb new refugees. One dimension of community capacity is the material infrastructure, especially affordable housing. One respondent said "Our number will depend on not only our consultation with [the] community to make sure that the political will is there, the community support is there, but also we look at factors like affordable housing, [which] is becoming more difficult in [city]" (R2). Some respondents indicated that the public perception of refugees, potentially influenced by politics, also affect the willingness of a community to support resettlement. One resettlement agency respondent described the community consultation process and its effect on resettlement decisions:

We have bilateral conversations with the office of the mayor, school districts, et cetera. And where we run into problems is if we have a mayor that's uncooperative, that is going to be a huge factor in deciding to resettle. But the fact is, ... I can't think of a mayor in any of the places we've ever worked who was a problem... [But] we would never resettle anyone in any community where we felt there was such a lack of receptivity that it would be problematic for the community or for the refugees. (R2)

This type of receptivity, or lack of it, to welcoming refugees in a community, can clearly support or hinder the resettlement process. Other respondents also discussed the "absorptive capacity" (R9) of certain cities to accept and integrate refugees into their social fabric, noting that the economic benefits and the financial challenges of resettlement can affect the community's receptivity as well. 


\section{Number to be resettled}

After discussing the factors that affect resettlement and how the decision should be made, respondents were asked how many refugees should be admitted to the U.S. for resettlement annually (see Table 2). Four respondents indicated that they believed the number should be higher than the ceiling President Obama set at 110,000 in his last year in office. This judgment was based on the belief that processing and resettlement capacity was high enough to take in more refugees, and that need was quite high; one proponent of this view argued that "Given the level of the crisis and the degree to which in my view we can actually sustain higher numbers, and I believe they would be to the benefit of the United States over the long term, I think I would push for a higher number [than 110,000]" (R4). One respondent indicated that there should be no ceiling at all. This respondent observed that ideally the system should "[treat] them the same as other immigrants ... [so] there would not be a numerical cap and there would not be a requirement of Congress to establish funding for these individuals" (R13). Five respondents indicated that the ceiling should be on par with recent averages, around 75,000 per year. The main reasons given for returning to the historic averages were that the number must be "set in such a way that Americans can support it" and that "this country can absorb that [range] of refugees, and we have the systems, and we have the partnerships" (R11). Only one respondent indicated that the ceiling should be "lowered further, to 25,000" because "Our own citizens' welfare should be primary" (R10a); of course, in FY 2020, this number was reduced beyond this bar to 18,000 (Trump, 2019). Five respondents did not provide a number.

\section{Discussion}

This analysis demonstrates the wide range of rationales that could factor into the determination of annual number of refugees admitted for settlement. These rationales include both moral considerations, such as the obligation to help vulnerable populations, as well as policy considerations, such as the promotion of American foreign policy interests or the economic costs and benefits of refugee resettlement in American communities. How should these various rationales be weighted when determining the refugee ceiling given the evident tradeoffs? And ultimately how many refugees should the U.S. admit each year? To explore these questions, we map the empirical data onto four of the theoretical frameworks introduced earlier. The mapping suggests an overall alignment between moral obligations and policy interests, such that the U.S. should admit considerably more refugees than the current administration has established. We explore this alignment between moral obligations and national self-interest, as well as the subsequent dual obligations of resettling a higher number of refugees than the present ceiling and working to improve the public perception of refugee resettlement.

\section{Humanitarianism}

Perhaps the clearest alignment between the themes that emerged from the interviews and ethical theory is the general support for the protection of vulnerable populations, a key tenet of humanitarianism. As discussed above, humanitarianism holds that the state has an obligation to help people in need, particularly when the costs of doing so are low. Many respondents endorsed an obligation to help vulnerable populations as an underlying value of the international refugee system, explicitly arguing that vulnerability should be the key factor in determining who is eligible for resettlement in the U.S. Literature on the long-term economic costs and benefits of refugee resettlement supports the argument that the costs of helping vulnerable refugees are low, including a never-released report written by the Department of Health and Human Services (HHS), which showed that refugees as a whole provide a net benefit to the U.S. economy of $\$ 63$ billion 
over the decade from 2005-2014 (HHS, 2017). These findings are supported by other studies in the literature as well (Evans \& Fitzgerald, 2017). It should be noted, however, that some respondents questioned whether the most efficient way of discharging obligations toward refugees is through resettlement as opposed to providing aid to overseas host countries.

\section{Duty to repair}

Another clear parallel can be seen between respondents' general agreement that refugees with connections to U.S. actions abroad should receive extra consideration, explored in the theme on fairness and reciprocity, and the theoretical literature on reparative duties. Respondents frequently described the relevant connections as those involving the U.S. military, either because a refugee helped the U.S. in some way, or because the U.S. military "mucked up" the situation in their home country. They often cited the U.S.'s destabilizing interventions in Iraq, Afghanistan, and Vietnam. The alignment between the empirical data and the theoretical justification for giving priority to refugees with these kind of connections to the U.S. suggests that this may be a powerful factor in swaying public opinion toward resettlement from countries affected by U.S. actions. Of course, without clear limits on this obligation, this rationale might support exceedingly high resettlement numbers given the extent to which U.S. economic and policy interventions have affected the lives of people across the globe. The most straightforward limit may be to derive reparative obligations only from U.S. intervention, but some may argue that this is an overly narrow restriction on the obligation to repair harms to which the U.S. has contributed. Furthermore, the obligations toward refugees generated by these relationships do not necessarily entail a right to resettlement within U.S. borders. Another concern about this justification is that it pays little heed to refugees, no matter how numerous or in need, whose persecution and resettlement need is not connected to U.S. policy.

\section{Legitimacy of the international state system}

Turning to the third theoretical approach, protecting the political legitimacy of the international state system, we find another parallel between the empirical data and the theoretical justifications for resettlement. Several of the foreign policy reasons for carrying out refugee resettlement, including stabilizing host countries and signaling solidarity, align with the argument that resettlement is necessary to ensure the continued legitimacy of the global system of states. Although respondents did not frame their reasoning in terms of political legitimacy, accepting refugees from states where they have taken refuge serves the goal of promoting those states' ability to function and continue to meet their obligations to receive refugees. Similarly, accepting refugees as a gesture of solidarity indicates that the U.S. remains committed to sharing in the countries perpetuates the legitimacy of the international state system, especially if other nations accept a fair share of refugees as well. This pairing of theory and data therefore might support an increased role for resettlement, rather than simply supporting the existence of an obligation that may be discharged through aid.

\section{Human rights}

Human rights considerations bear on refugee admissions by requiring that the number be determined by factors other than animus toward certain religious groups or the countries from which refugees are fleeing. All respondents, including those who otherwise felt that the overall ceiling should be lower, rejected religion, race, and nationality as bases for admissions decisions. The duty not to engage in discrimination does not directly address the criteria for determining the 
number of refugees to admit, but human rights considerations do apply to setting the criteria for admissions.

\section{Alignment between self-interest and moral duty}

Joseph Carens argues that when morality and self-interest are aligned, it becomes much easier for people to accept moral arguments in favor of a particular course of action, and that this is especially apparent in politics and policymaking. On refugee policy, however, Carens observed:

Refugee policy is today one of those areas where the gap between what morality requires and what serves even long run self-interest is so great that interest can do very little work in supporting morality ... There is now, I fear, a deep conflict between what morality requires of democratic states with respect to the admission of refugees and what democratic states and their existing populations see as their interests (Carens, 2013, p. 223).

The findings presented here suggest that Carens' fears regarding the misalignment between morality and self-interest in the case of refugee policy may be overblown. The interview themes indicate that admitting refugees is often in the interest of the U.S. and also serves to promote moral values to which most Americans subscribe. Indeed, given the policy goals and underlying values that respondents report are served by refugee admissions, even Carens might concede that there is far greater alignment on the wisdom and moral necessity of admitting refugees than he initially posited. Most respondents also indicated that the U.S. has both the practical capacity and the moral obligation to admit many more refugees than the Trump Administration established.

Of course, this argument must be situated in the context of real communities that might receive refugees. Although we contend that self-interest and moral duty align on resettlement, not all localities (or their elected leaders) are going to agree that resettlement promotes their interests, even when confronted with evidence from the literature. See, for example, the outcry from some (mostly Republican) state governors who indicated that they would not accept Syrian refugees after the 2015 Paris attacks, and the response from other (Democratic) governors who insisted they would continue to welcome them (Seipel, 2015).

\section{Political will and dual obligations}

In their discussion of the barriers to resettlement, many respondents described the limitations on the capacity or willingness of the U.S. to process and resettle refugees. These limitations were frequently related to the budgets of the State Department for resettlement agencies and receiving communities that provide public benefits, education and social services to resettled refugees. These budgets, many respondents indicated, are in turn constrained by political will to support the resettlement program in the face of domestic political constituencies opposed to immigration generally. We follow Matthew Gibney in arguing that the U.S. is dually obligated to admit as many refugees as processing capacity and refugee support factors allow and to engage in proactive steps to seek to increase support for refugee resettlement, especially given the low (or, over time, nonexistent) costs of resettlement. He writes:

[T] he conception of 'costs' at the heart of humanitarianism is partly a social and political construct...

[H] umanitarianism [imposes] on governments an additional responsibility - a duty to work towards reshaping the political space in which they find themselves in ways more conducive to the reception of refugees and asylum seekers. (Gibney, 2004, p. 244, original emphasis).

This argument resonates with the empirical findings of this study that real limits to the capacity to resettle refugees are products of political will, both at the local and national levels. The argument also tracks with the lack of evidence that resettled refugees add a serious economic or social burden on those American communities willing to accept them. Gibney suggests that 
policymakers reshape the political space to lower the barriers to meeting our obligations toward refugees in three ways: (1) by reshaping public opinion on the moral importance of asylum; (2) by participating in sharing the burdens of resettlement; and (3) by tackling the causes of forced migration, reducing the need for resettlement overall (Gibney, 2004, pp. 244-249). Such actions also reflect the U.S. self-interest findings of this study, in that they (1) could support the domestic policy goal of gaining political support, while (2) supporting the foreign policy goal of showing solidarity with host countries and (3) maintaining host country stability.

\section{Limitations}

This study has several limitations. Foremost among these is the limited representation of current or former Trump administration political appointees among respondents as all but two of those contacted declined to participate in interviews. Additionally, some career State Department officials also declined to participate. Although these perspectives are missing from the interviews, the public positions of the Trump administration on refugee resettlement have been widely documented in official statements, speeches, tweets, and media coverage. While these public positions may not entirely capture the reasoning of the administration, we believe they are sufficient to allow inferences about the policy and moral reasons grounding its setting of the refugee resettlement ceiling. Data collection and analysis were also slightly limited by the refusal by a handful of the respondents to be recorded; although notes were taken during these interviews, they cannot capture the full detail of respondents' views. Additionally, the timing of interviews, taking place in 2017-2018 during a major shift in the refugee resettlement landscape, may have influenced the responses of key informants by leading them to identify as important (or not important) those factors being leveraged by the Trump administration. Researcher bias presents an additional potential limitation to this study. Researchers attempted to mitigate this effect through reflexive memo-writing, the use of multiple coders for every interview transcript, and through theoretical triangulation.

\section{Conclusion}

This project sought to explore the moral and policy factors that should be considered when determining the number of refugees to resettle in the U.S. We find that various goals, values, and barriers/facilitators interact to form a complicated system of motivational factors that influence the annual refugee ceiling.

On a practical level, we find that key informants believe that the U.S. and its refugee resettlement agencies have the capacity to resettle far more refugees than in the past, though there may be some limits based on the complexities of security vetting. We recognize, however, that pragmatic factors including history, resettlement traditions, budget considerations, the high cost of resettlement, and the need to maintain community acceptance and political support for the program are germane to determining the number of refugees accepted for resettlement. Further, the attempt to rapidly expand the number of refugees resettled put strains on the system. We conclude that as a starting point for future resettlement, the number of refugees actually resettled should be set in the 70-80,000 range that was used from 2001-2015, with gradual growth to meet the anticipated growing needs for refugee resettlement. This approach is also consistent with the tradition that the U.S. has taken on average approximately half the refugees resettled worldwide in order to equitably share burdens, especially given that refugees account for less than half of all forcibly displaced migrants in the world and our above discussion of obligations toward asylum seekers (UNHCR, 2018). From a process and governance point of view, we concur with a Heritage Foundation policy recommendation that dramatic departures from the traditional 
approach and historical number should be approved by Congress in accordance with its statutory oversight role for the program (Enos et al., 2017).

In addition to these practical recommendations, we also reach several theoretical conclusions. Through a mapping of the empirical findings of this study onto the political and moral theory literature, we find that a variety of theoretical positions support the position that the U.S. has a moral obligation to resettle refugees. We find that Matthew Gibney's theory of humanitarianism is particularly aligned with the empirical findings of this study regarding the reasons for promoting refugee resettlement. Further, we demonstrate that Gibney's conclusion that there exists a secondary obligation to actively alter the political climate surrounding refugee resettlement resonates with the empirical findings of this study. Future work should explore the means by which policymakers, in accordance with Gibney's suggestion, can shape public opinion of refugee resettlement in order to reduce the public perception of the costs of upholding moral obligations to protect vulnerable populations.

\section{Funding}

This work was supported by a Johns Hopkins University "Exploration of Practical Ethics" grant.

\section{ORCID}

Rachel Fabi (iD http://orcid.org/0000-0003-3027-7812

\section{References}

Betts, A., \& Collier, P. (2017). Refuge: Transforming a broken refugee system. Penguin Random House.

Blitzer, J. (2017). How Stephen Miller single-handedly got the U.S. to accept fewer refugees. The New Yorker. https://www.newyorker.com/news/news-desk/how-stephen-miller-single-handedly-got-the-us-to-accept-fewerrefugees

Cane, M. A., Kelley, C. P., Kushnir, Y., Mohtadi, S., \& Seager, R. (2015). Climate change in the fertile crescent and implications of the recent Syrian drought. Proceedings of the National Academy of Sciences, 112(11), 3241-201421533. doi:10.1073/pnas.1421533112

Carens, J. H. (2013). The ethics of immigration. Oxford University Press.

Charmaz, K. (2006). Constructing grounded theory: A practical guide through qualitative analysis. Sage.

Enos, O., Inserra, D., \& Meservey, J. (2017). Backgrounder: The U.S. refugee admissions program: A roadmap for reform (Report No. 3212). The Heritage Foundation.

Evans, W., \& Fitzgerald, D. (2017). The economic and social outcomes of refugees in the United States: Evidence from the ACS (Report No. w23498). National Bureau of Economic Research.

Field, P. A., \& Morse, J. M. (1995). Qualitative research methods for health professionals. Sage.

Fine, S., \& Ypi, L. (Eds.). (2016). Migration in political theory: The ethics of movement and membership. Oxford University Press.

Gibney, M. J. (2004). The ethics and politics of asylum: Liberal democracy and the response to refugees. Cambridge University Press.

Hirschfeld Davis, J., Jordan, M. (2017, September 26). Trump plans 45,000 limit on refugees admitted to U.S. The New York Times. https://www.nytimes.com/2017/09/26/us/politics/trump-plans-45000-limit-on-refugees-admitted-to-us.html

Hosein, A. (2019). The ethics of migration: An introduction. Routledge.

The International Federation of Red Cross and Red Crescent Societies. (2018). Fundamental principles of the Red Cross and Red Crescent. https://media.ifrc.org

Migration Policy Insitute. (2019). U.S. annual refugee resettlement ceilings and number of refugees admitted, 1980-present. https:/www.migrationpolicy.org/programs/data-hub/charts/us-annual-refugee-resettlement-ceilings-and-number-refugees-admitted-united

Miller, D. (2016). Strangers in our midst. Harvard University Press.

Owen, D. (2016). In loco civatis. In S. Fine \& L. Ypi (Eds.), Migration in political theory: The ethics of movement and membership. (pp. 269-291). Oxford University Press. 
Patton, M. Q. (1999). Enhancing the quality and credibility of qualitative analysis. Health Services Research, 34(5 Pt 2), 1189-1208.

Pogge, T. (1997). Migration and poverty. In V. Bader (ed.) Citizenship and exclusion (pp. 12-27). Palgrave Macmillan.

Refugee Act of 1980 (2011). 94 Stat. 102, codified at 8 USCS $\$ 1157$.

Rejected report shows revenue brought in by refugees. (2017, September 19). New York Times. https://www.nytimes. com/interactive/2017/09/19/us/politics/document-Refugee-Report.html

Seipel, A. (2015, November 17). 30 governors call for halt to U.S. Resettlement of Syrian Refugees. NPR. https:// www.npr.org/2015/11/17/456336432/more-governors-oppose-u-s-resettlement-of-syrian-refugees

Singer, P., \& Singer, R. (2010). The ethics of refugee policy. In J. Fishkin \& R. Gooden (Eds.), Population and political theory. Wiley-Blackwell.

Trump, D. (2019). Presidential determination on refugee admissions for fiscal year 2020. Presidential Memoranda. The White House.

United Nations. (1951, July 28). Convention relating to the status of refugees. United Nations conference of plenipotentiaries on the status of refugees and Stateless Persons, Geneva. https://www.unhcr.org/en-us/protection/travaux/40a8a7394/final-act-united-nations-conference-plenipotentiaries-status-refugees-stateless.html

UN General Assembly. (1948). Universal declaration of human rights (217 [III] A).

United Nations High Commissioner for Refugees. (2019). Figures at a glance. https://www.unhcr.org/en-us/figuresat-a-glance.html

U.S. annual refugee resettlement ceilings and number of refugees admitted, 1980-Present. (2019). MPI Data Hub. https://www.migrationpolicy.org/programs/data-hub/charts/us-annual-refugee-resettlement-ceilings-and-numberrefugees-admitted-united

U.S. Department of Health and Human Services. (2012). Migration and refugee assistance, fiscal year 2012: Congressional presentation document. Bureau of Population, Refugees, and Migration.

U.S. Department of Health and Human Services, Office of the Assistant Secretary for Planning and Evaluation, U.S. Department of State. (2017, July 29). The fiscal costs of the US refugee admissions program at the federal, state, and local levels, from 2005-2014. [draft]. Bureau of Population, Refugees, and Migration.

U.S. Department of Health and Human Services, U.S. Department of Homeland Security, U.S. Department of State. (2018). Proposed refugee admissions for fiscal year 2019: Report to congress. Bureau of Population, Refugees, and Migration. 